\title{
Suitability of selection criteria as a measure of outcome of medical graduates: University of Colombo
}

\author{
D. S. G. Mettananda' , *V. P. Wickramasinghe ${ }^{2}$, J. Kudolugoda Arachchi ${ }^{2}$, Sanath P. Lamabadusuriya ${ }^{3}$, \\ R. Ajanthan ${ }^{4}$ D. Kottahachchis,
}

The Ceylon Journal of Medical Science 2006; 49: 1-12

\begin{abstract}
A prime obstacle faced by a medical educator is selecting the right student to be trained as a doctor, and the general consensus is that this is also the most difficult task. This study was designed to evaluate the effects of selected outcome measures on outcome performance of medical undergraduates of the University of Colombo.
\end{abstract}

A retrospective cohort study was conducted using the performance (marks) of students of 4 batches GCE (A/L) 1993 through to 1996). GCE (A/L) aggregate marks, attempt of entry, district of entry, English language proficiency and sex were tested as predictors of success. Results of main assessments were considered as measures of success. Relationship between outcome measures and outcome predictors were assessed using the multiple logistic regression model.

Data of 699 students were analyzed and $82 \%$ of students entered from the Colombo district. A higher percentage of first attempters (at GCE A/L) performed well and obtained classes. Entering medical school from first two GCE A/L examination attempts was a significant positive predictor of passing any examination (odds ratio 3.2 to 7.5) or obtaining honors (odds ratio 2.8 to 16.0). Attempt of entry predicted $5.4 \%$ of the outcome (pass or fail) in university performance. Correlation between the GCE A/L aggregate mark and the student's position in order of merit for the internship appointments was $-0.37(p<0.001)$.

A combination of factors should be used in the selection process of students to embark on the undergraduate process as any single factor is a poor predictor of outcome of performance. We believe that the number of attempts allowed to sit for GCE A/L in order to gain entry to a medical school as well as other degree courses should be confined to two attempts.

Key words: selection criteria, medical graduates, medical education.

\section{Demonstrator}

2. Lecturer

3. Senior Professor

4. Senior Lecturer, Department of Paediatrics, Faculty of Medicine, University of Colombo, Sri Lanka.

5. Director Planning, University Grants Commission.

* Author for correspondence E-mail: pujitha@srilankaehealth.com. Received on June 26, 2006 and revised version accepted on September 25, 2006. 


\section{Introduction}

Medicine is a vast subject requiring knowledge, skills and competence in multiple disciplines. Role of a modern doctor ranges from a traditional prescriber through effective health educator to a skillful microscopic surgeon. Doctors today thus need training in numerous, fields both traditional and otherwise. Medical schools all over the world have revised their curricula to offer medical graduates a more elaborate training. The ultimate objective is to produce a competent, compassionate, caring doctor, who would be able to meet the needs of the community they serve and be well equipped to face the future challenges.

The prime obstacle faced by a medical educator in achieving these goals is in the selection of the right student. The general consensus is also that this is the most difficult task $(1,2)$. Identification of reliable predictors of success in medical school performance is difficult but is essential to improve the objectivity, fairness and effectiveness of the selection procedures. Selection of medical undergraduates differs not only from country to country but also from institute to institute. Different medical schools use different criteria alone or in combination to improve the effectiveness of the selection. These include cognitive factors like previous academic performance and non-cognitive factors like personality, interviews, references, personal statements, extracurricular activities, motivation, learning styles, linguistic and communication skills. Sometimes demographic factors such as sex and ethnicity are considered as relevant (1).

In Sri Lanka selecting medical students to the six state medical faculties is uniform and is described elsewhere (3). This selection criterion has come under criticism recently as it has raised several important questions - Does the GCE A/L aggregate mark predict their future success in the medical faculty? Is it fair to use a single cut off mark for all students irrespective of their number of attempts? Is it worth wasting a valuable year of a youth in attempting the GCE A/L examination for a third time in order to gain entry to a medical school?

A recent meta-analysis of factors associated with success in medical schools in many countries found that the previous academic performance is a good predictor but not a perfect one of achievement in medical training (1). Previous studies investigating the relationship between performance at the GCE A/L examination and performance at medical school examinations in Sri Lanka have yielded conflicting results (3). A study done at University of Peradeniya concluded that the GCE A/L examination mark taken in conjunction with the number of attempts to be a useful predictor of the performance at the second MBBS examination (4). A study done later in the same university concluded that the GCE A/ $\mathrm{L}$ aggregate mark has no correlation with the students' subsequent performance, even though $\mathrm{A} / \mathrm{L}$ and 2 nd MB marks showed a correlation of 0.4 (5). A study done at the University of Colombo showed that the attempt of entry was a positive predictor of later performance at university (6). Authors from University of Kelaniya concluded that the GCE A/L aggregate mark has a much lower predictive value of subsequent performance at medical faculty accounting for $2-5 \%$ (3). However, there are several shortcomings seen in the Kelaniya study, such as the variation observed in the independent (predictive) variables. This is very small in the selected medical faculty and information on some important predictors 
such as proficiency in English language and the number of attempts at the GCE A/L examination is absent $(3,7)$.

Therefore it is timely that effective predictors of medical undergraduates' performance are identified. This could be used to select the best group of students to undergo this arduous course and become competent doctors. This will also direct some students who do not fit with the selection criteria to take up a more appropriate career. It is timely and useful to carry out detailed research on the predictors of medical graduates' performance and perhaps revise the selection criteria in order to admit the most suitable group of students to undergo medical training. We attempt to contribute to this badly needed pool of data by analyzing the performance of the medical undergraduates of the Colombo medical faculty.

\section{Objective}

To evaluate the effects of performance at GCE A/L examination, English language proficiency and gender on the undergraduate performance of the students of Faculty of Medicine, University of Colombo.

\section{Material and Methods}

A retrospective cohort study was conducted at the Faculty of Medicine, University of Colombo. Students of 4 batches selected to the faculty on their performance at GCE A/L examinations held from 1993 through to 1996 , and who reached the final year of study with the same stipulated batch, were included in the study.

Aggregate marks of the $4 \mathrm{~A} / \mathrm{L}$ subjects (out of 400) and the attempt of obtaining the required aggregate, district of entry,
English language proficiency and sex were tested as predictors of success. District of entry denotes the district from which the student was considered for entry into the faculty according to the University Grants Commission (UGC) regulations. English language proficiency was assessed by the grade obtained for English language at the General Certificate of Education Ordinary Level (GCEO/L) examination.

Results of six major student assessments, 'Cumulative MBBS result' and student's position in all island merit list were considered as measures of success of their performance in the faculty. The six major assessments were Introductory Basic Sciences Module (IBSM) (comparable to second MBBS), Introductory Basic and Applied Sciences Stream (IBASS) (comparable to third MBBS without community medicine), Community Stream (CS) (comparable to community medicine), Behavioural Sciences Stream (BSS), Clinical Sciences Stream (CSS) and End of Course Assessment of the Clinical Sciences Stream (ECACSS) (comparable to final MBBS). 'Cumulative MBBS result' is an overall mark given out of all six assessments and it is considered as the most appropriate reflector of the students' performance throughout their 5-year academic career.

GCE A/L aggregate mark and the district of entry were obtained from the UGC data base while the number of attempts at GCE A/L, result of GCE O/L English language, results of university examinations and merit order for internship appointments were gathered by perusal of documents from the administrative department (Dean's office) of the Faculty of Medicine, University of Colombo. 
Ethical clearance was obtained from the Ethical Review Committee of the Faculty of Medicine, University of Colombo.

\section{Statistics}

Multiple logistic regression model was applied to assess the relationship between outcome measure and outcome predictors (possible selection variables) (8). Cumulative MBBS result was used as the outcome variable. Two dichotomous variables pertaining to outcome variables were used. First is passing or failing the examination and second is obtaining a class or not.

Spearman rank correlation was used to describe the relationship between rank position to obtain internship and GCE A/L aggregate and between rank position and attempt of entry.

SPSS and NCSS/PASS 2000 statistical computer packages for windows were used for data analysis.

\section{Results}

Seven hundred and forty three students were registered in the faculty during the stipulated study period. Ninety four percent of them reached the final year with their respective batch, and the remaining forty four students were excluded from the main analysis.

Total study population consisted of 699 students and their characteristics are shown in Table 1. Eighty two percent entered from Colombo district while the remainder entered from 15 other administrative districts. More than 10 students were selected from each of the following districts; Matara, Jaffna, Galle, Gampaha and Kurunegala. No student was selected to the Colombo Medical Faculty from administrative districts of Matale, Hambanthota, Polonnaruwa,
Moneragala, Ampara, Vavuniya, Mulativu, Kilinochchi and Mannar. Mean GCE A/L aggregate mark showed a slight decline over the 4 years. Aggregate mark ranged from 283 to 356 and $62 \%$ of students had scored above 300 marks. GCE O/L English language results were available only for 406 $(58.1 \%)$ students. Majority $(86.9 \%)$ of them had distinctions while none had failed in the subject of English language.

Table 2 shows the performance at the six main examinations and the 'Cumulative MBBS results' of the four batches. In all assessments, a higher percentage of first attempters (at GCE A/L) performed well and obtained classes (First, Second upper or Second lower) than the second or third attempters. Performances of the second attempters were better than the third attempters (Table 3). Being a GCE A/L first or second attempter was a significant independent positive predictor of passing any of the examinations (odds ratio varied from 3.2 to 7.5 ) or obtaining honours (odds ratio varied between 2.8 to 16.0 ) (Table 4). Obtaining an aggregate over 300 marks at GCE A/L was a significant positive predictor of passing IBSM, CSS, ECACSS or obtaining honours at IBASS, CSS, ECACSS and 'Cumulative MBBS result'. Students who obtained a distinction for English language at GCE O/L had an increased chance of passing CS, CSS and 'Cumulative MBBS result' and obtaining honours at all examinations except CSS and ECACSS. Being a female was a significant predictor of passing BSS, CS and 'Cumulative MBBS result' and obtaining honours at IBASS, BSS, CS, CSS and 'Cumulative MBBS result'. Being a student from the Colombo district had no effect on faculty performance except for the BSS examination.

Based on the multiple logistic regression model, attempt of entry predicted $5.4 \%$ of 
the outcome (pass or fail) in university performance. However, adding the $\mathrm{A} / \mathrm{L}$ aggregate, obtaining a distinction in English at GCE O/L, entering from Colombo district or being a female student did not improve the prediction. When outcome measure was considered as obtaining a class, attempt of entry predicted $16.1 \%$ of variance while adding the GCE A/L aggregate improved it to $17.7 \%$. Obtaining a distinction in English improved it to $19.8 \%$. Entering from Colombo district or being a female student did not improve the prediction.

Table 1. Characteristics of the study population

\begin{tabular}{|c|c|c|c|c|}
\hline $94 / 95$ & $95 / 96$ & $96 / 97$ & $97 / 98$ & \\
\hline No. Registered & 181 & 185 & 186 & 191 \\
\hline No. in the professorial batch (\%) & $172(95.0)$ & $172(93.0)$ & $184(98.9)$ & $173(90.6)$ \\
\hline \multicolumn{5}{|l|}{ Sex } \\
\hline Male (\%) & $119(69.6)$ & $103(60.2)$ & $118(64.1)$ & $104(60.1)$ \\
\hline Female (\%) & $52(30.4)$ & $68(39.8)$ & $66(35.9)$ & $69(39.9)$ \\
\hline \multicolumn{5}{|l|}{ District of entry } \\
\hline Colombo $(\%)$ & $141(82.5)$ & $141(82.5)$ & $143(77.7)$ & $149(86.1)$ \\
\hline Other districts (\%) & $30(17.5)$ & $30(17.5)$ & $41(22.3)$ & $24(13.9)$ \\
\hline \multicolumn{5}{|l|}{ AL attempt } \\
\hline First attempt (\%) & $108(63.2)$ & $103(60.2)$ & $99(53.8)$ & $94(54.3)$ \\
\hline Second attempt (\%) & $50(29.2)$ & $58(33.9)$ & $70(38.0)$ & $67(38.7)$ \\
\hline Third attempt (\%) & $13(7.6)$ & $10(5.8)$ & $15(8.2)$ & $12(6.9)$ \\
\hline \multicolumn{5}{|l|}{ AL aggregate } \\
\hline Mean & 312.1 & 305.6 & 304.6 & 299.3 \\
\hline Standard deviation & 10.5 & 12.8 & 12.0 & 12.6 \\
\hline OL English result (n) & (158) & (125) & (39) & (84) \\
\hline Distinction (\%) & $139(88.0)$ & $104(83.2)$ & $32(82.1)$ & $78(92.9)$ \\
\hline Credit (\%) & $15(9.5)$ & $20(16.0)$ & $4(10.3)$ & $5(6.0)$ \\
\hline Simple pass $(\%)$ & $4(2.5)$ & $1(0.8)$ & $3(7.7)$ & $1(1.2)$ \\
\hline
\end{tabular}


Table 2. Performances of undergraduates of each batch in their examinations

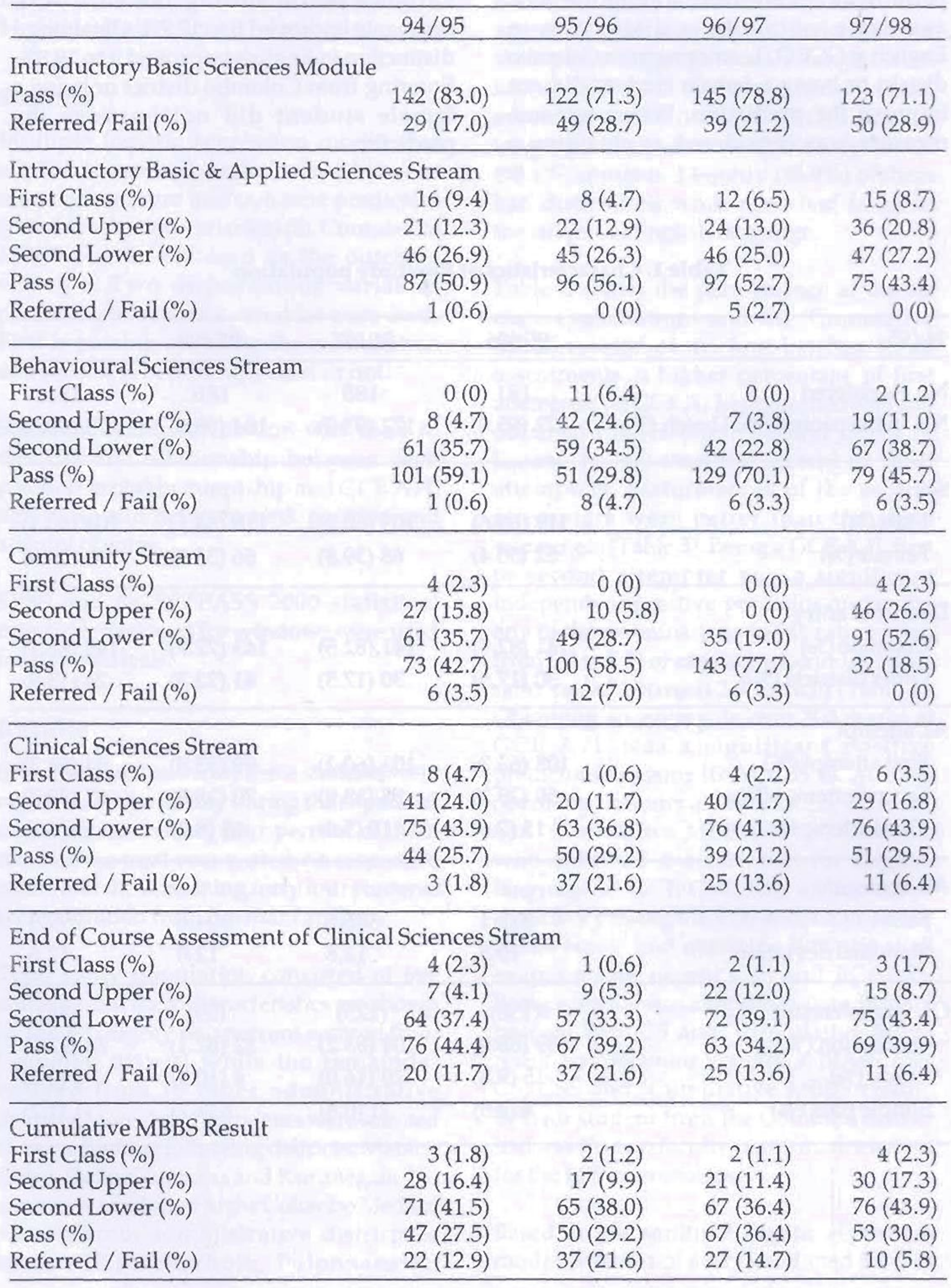


Table 3. Performances of undergraduates in their examinations according to attempt of entry (GCE $\mathrm{A} / \mathrm{L}$ examination)

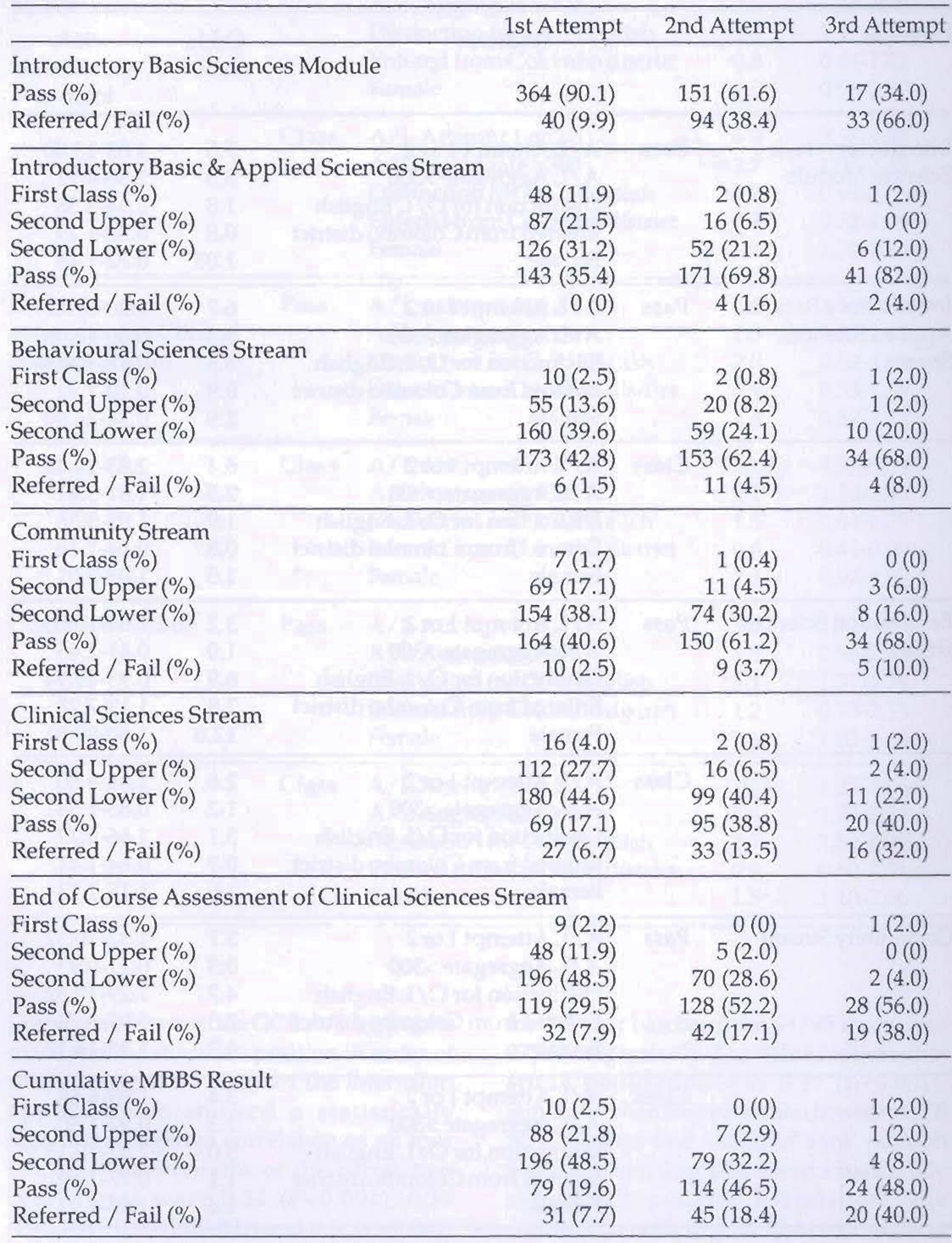

In this table the data from all 4 batches of students have been pooled 
Table 4. Predictors of performance of each undergraduate examination of medical curriculum, University of Colombo

\begin{tabular}{|c|c|c|c|c|}
\hline Outcome & & Predictor & $\begin{array}{l}\text { Odds } \\
\text { ratio }\end{array}$ & $\begin{array}{c}95 \% \\
\text { Confidence } \\
\text { interval }\end{array}$ \\
\hline $\begin{array}{l}\text { Introductory Basic } \\
\text { Sciences Module }\end{array}$ & Pass & $\begin{array}{l}\text { A/L Attempt } 1 \text { or } 2 \\
\text { A/L Aggregate }>300 \\
\text { Distinction for O/L English } \\
\text { Entered from Colombo district } \\
\text { Female }\end{array}$ & $\begin{array}{l}7.5 \\
3.3 \\
1.8 \\
0.8 \\
1.03\end{array}$ & $\begin{array}{l}4.03-13.80 \\
2.30-4.71 \\
0.94-3.38 \\
0.50-1.29 \\
0.72-1.48\end{array}$ \\
\hline \multirow[t]{2}{*}{$\begin{array}{l}\text { Introductory Basic \& } \\
\text { Applied Sciences } \\
\text { Stream }\end{array}$} & Pass & $\begin{array}{l}\text { A/L Attempt } 1 \text { or } 2 \\
\text { A/L Aggregate }>300 \\
\text { Distinction for O/L English } \\
\text { Entered from Colombo district } \\
\text { Female }\end{array}$ & $\begin{array}{l}6.7 \\
3.3 \\
6.8 \\
0.9 \\
2.9\end{array}$ & $\begin{array}{l}1.20-37.62 \\
0.60-18.08 \\
0.42-109.88 \\
0.10-7.92 \\
0.34-24.90\end{array}$ \\
\hline & Class & $\begin{array}{l}\text { A/L Attempt } 1 \text { or } 2 \\
\text { A/L Aggregate }>300 \\
\text { Distinction for O/L English } \\
\text { Entered from Colombo district } \\
\text { Female }\end{array}$ & $\begin{array}{l}6.4 \\
2.5 \\
1.9 \\
0.8 \\
1.5\end{array}$ & $\begin{array}{l}2.83-14.42 \\
1.81-3.41 \\
1.03-3.36 \\
0.54-1.18 \\
1.08-2.01\end{array}$ \\
\hline \multirow[t]{2}{*}{$\begin{array}{l}\text { Behavioural Sciences } \\
\text { Stream }\end{array}$} & Pass & $\begin{array}{l}\text { A/L Attempt } 1 \text { or } 2 \\
\text { A/L Aggregate }>300 \\
\text { Distinction for O/L English } \\
\text { Entered from Colombo district } \\
\text { Female }\end{array}$ & $\begin{array}{l}3.2 \\
1.0 \\
6.9 \\
2.9 \\
12.0\end{array}$ & $\begin{array}{l}1.04-10.00 \\
0.41-2.45 \\
0.95-49.94 \\
1.19-7.28 \\
1.60-89.81\end{array}$ \\
\hline & Class & $\begin{array}{l}\text { A/L Attempt } 1 \text { or } 2 \\
\text { A/L Aggregate }>300 \\
\text { Distinction for O/L English } \\
\text { Entered from Colombo district } \\
\text { Female }\end{array}$ & $\begin{array}{l}2.8 \\
1.2 \\
3.1 \\
0.9 \\
1.6\end{array}$ & $\begin{array}{l}1.45-5.50 \\
0.85-1.58 \\
1.66-5.77 \\
0.64-1.41 \\
1.15-2.13\end{array}$ \\
\hline \multirow[t]{2}{*}{ Community Stream } & Pass & $\begin{array}{l}\text { A/L Attempt } 1 \text { or } 2 \\
\text { A/L Aggregate }>300 \\
\text { Distinction for } \mathrm{O} / \mathrm{L} \text { English } \\
\text { Entered from Colombo district } \\
\text { Female }\end{array}$ & $\begin{array}{l}3.7 \\
0.3 \\
4.7 \\
2.3 \\
4.2\end{array}$ & $\begin{array}{l}1.32-10.32 \\
0.11-0.93 \\
1.29-17.32 \\
0.97-5.70 \\
1.23-14.12\end{array}$ \\
\hline & Class & $\begin{array}{l}\text { A/L Attempt } 1 \text { or } 2 \\
\text { A/L Aggregate }>300 \\
\text { Distinction for O/L English } \\
\text { Entered from Colombo district } \\
\text { Female }\end{array}$ & $\begin{array}{l}3.4 \\
1.3 \\
5.0 \\
1.1 \\
1.4\end{array}$ & $\begin{array}{l}1.69-6.68 \\
0.97-1.80 \\
2.52-10.13 \\
0.77-1.69 \\
1.03-1.91\end{array}$ \\
\hline
\end{tabular}


Table 4 continued

\begin{tabular}{|c|c|c|c|c|}
\hline $\begin{array}{l}\text { Clinical Sciences } \\
\text { Stream }\end{array}$ & Pass & $\begin{array}{l}\text { A/L Attempt } 1 \text { or } 2 \\
\text { A/L Aggregate }>300 \\
\text { Distinction for O/L English } \\
\text { Entered from Colombo district } \\
\text { Female }\end{array}$ & $\begin{array}{l}4.6 \\
2.3 \\
3.6 \\
0.8 \\
1.6\end{array}$ & $\begin{array}{l}2.41-8.86 \\
1.44-3.79 \\
1.17-10.90 \\
0.44-1.62 \\
0.93-2.67\end{array}$ \\
\hline & Class & $\begin{array}{l}\text { A/L Attempt } 1 \text { or } 2 \\
\text { A/L Aggregate }>300 \\
\text { Distinction for O/L English } \\
\text { Entered from Colombo district } \\
\text { Female }\end{array}$ & $\begin{array}{l}4.9 \\
2.7 \\
1.7 \\
0.8 \\
1.7\end{array}$ & $\begin{array}{l}2.58-9.24 \\
1.95-3.68 \\
0.94-3.05 \\
0.52-1.19 \\
1.20-2.31\end{array}$ \\
\hline $\begin{array}{l}\text { End of course } \\
\text { assessment of Clinical } \\
\text { Sciences Stream }\end{array}$ & Pass & $\begin{array}{l}\text { A/L Attempt } 1 \text { or } 2 \\
\text { A/L Aggregate }>300 \\
\text { Distinction for O/L English } \\
\text { Entered from Colombo district } \\
\text { Female }\end{array}$ & $\begin{array}{l}4.8 \\
1.5 \\
2.0 \\
0.9 \\
1.4\end{array}$ & $\begin{array}{l}2.56-8.86 \\
1.01-2.41 \\
0.82-4.88 \\
0.53-1.69 \\
0.87-2.23\end{array}$ \\
\hline & Class & $\begin{array}{l}\text { A/L Attempt } 1 \text { or } 2 \\
\text { A/L Aggregate }>300 \\
\text { Distinction for O/L English } \\
\text { Entered from Colombo district } \\
\text { Female }\end{array}$ & $\begin{array}{l}16.0 \\
2.1 \\
1.5 \\
0.6 \\
1.3\end{array}$ & $\begin{array}{l}4.93-51.95 \\
1.54-2.88 \\
0.84-2.73 \\
0.41-0.90 \\
0.97-1.80\end{array}$ \\
\hline Cumulative MBBS & Pass & $\begin{array}{l}\text { A/L Attempt } 1 \text { or } 2 \\
\text { A/L Aggregate }>300 \\
\text { Distinction for O/L English } \\
\text { Entered from Colombo district } \\
\text { Female }\end{array}$ & $\begin{array}{l}5.0 \\
1.5 \\
3.1 \\
1.2 \\
1.6\end{array}$ & $\begin{array}{l}2.72-9.29 \\
0.98-2.35 \\
1.37-6.79 \\
0.73-2.13 \\
1.02-2.66\end{array}$ \\
\hline & Class & $\begin{array}{l}\text { A/L Attempt } 1 \text { or } 2 \\
\text { A/L Aggregate }>300 \\
\text { Distinction for O/L English } \\
\text { Entered from Colombo district } \\
\text { Female }\end{array}$ & $\begin{array}{l}10.4 \\
2.4 \\
2.7 \\
0.9 \\
1.5\end{array}$ & $\begin{array}{l}4.35-24.66 \\
1.73-3.24 \\
1.50-4.95 \\
0.60-1.31 \\
1.10-2.06\end{array}$ \\
\hline
\end{tabular}

Correlation between the GCE A/L aggregate mark and the student's position in order of merit (numerical value) for the internship appointments showed a statistically significant negative correlation in all four batches. The strengths of the correlation coefficients were $0.34(\mathrm{P}<0.001), 0.39$ $(\mathrm{P}<0.001), 0.39(\mathrm{P}<0.001)$ and $0.36(\mathrm{P}<0.001)$ for the four batches from $94 / 95$ through to $97 / 98$ respectively. The value for the entire study population was $0.37(\mathrm{p}<0.001)$. Similarly when the correlation between GCE $\mathrm{A} / \mathrm{L}$ attempt and students' rank position was evaluated they all showed a statistically significant positive correlation. The correlation coefficients for the 4 batches were 
$0.36(\mathrm{p}<0.001), 0.40(\mathrm{p}<0.001), 0.47(\mathrm{p}<0.001)$ and $0.43(p<0.001)$ from $94 / 95$ through to $97 / 98$ respectively. The overall value for the entire group was $0.41(p<0.001)$.

Out of the 44 students who were excluded from the main analysis, 2 were selected to the faculty using different selection criteria, a foreign (Pakistan) student and a student selected to the faculty based on London A/L results, 2 died and 3 left the faculty within one year of entry. Thirty seven students missed their respective batches. Characteristics of students who missed their batches were evaluated. $70 \%$ of them were males. Mean mark obtained at G.C.E. (A/L) examination was $296.2(\mathrm{SD} \pm 12.0)$. Only $8 \%$ of them entered the faculty in their first attempt at G.C.E. (A/L) while $78 \%$ and $14 \%$ entered in their 2 nd and $3 \mathrm{rd}$ attempts respectively. Seventy six percent of them completed the MBBS degree with the immediate junior batch while $13 \%$ had to wait for 2 years. Another $11 \%$ did not complete the degree even after 2 years.

\section{Discussion}

Medicine is the most sought after and the longest undergraduate course in Sri Lanka, which creates tremendous stress for some students. Medical graduates' duties are diverse and needs a variety of skills to attend to their day to day work efficiently. Therefore it is of utmost importance to select the best to start the training course. If the best fit could not be found they will ultimately get frustrated, dropout and fade away during the long undergraduate journey. As stated earlier the most difficult task is to select the best. Traditionally selection had been based on academic performance by way of an entry examination. Conventionally three attempts were allowed to obtain the required grading. Shortcomings of this are well understood and past academic performance alone is not the best predictor of future academic success as a medical undergraduate. However, the ideal criteria for selection are not established and not well researched (1). These criteria may vary from one country to another depending on the social needs.

In our study the best predictor of medical undergraduate performance was the GCE A/L attempt at which students obtained the relevant mark. Those who gained admission to a medical school in their first or second attempt always did better than those who entered at their third attempt. The first or second attempters performed better in both types of curricula (6). This was not only the case in Colombo but also at Peradeniya $(4,5)$. GCE A/L aggregate alone was a poor predictor of later performance at individual examinations as well as at overall performance assessed by the Cumulative MBBS result. Consistent with many other studies $(1,3)$ girls of the Colombo medical faculty performed better in passing as well as in obtaining honors at examinations compared to the boys. Although we had an incomplete data set regarding English proficiency, it clearly showed that a better knowledge in English (assessed by a distinction) always helped a student to obtain a better result.

Students for all six medical faculties are being selected on a common examination, $i e$. GCE A/L. Once students get enrolled to the respective medical schools they have to follow different curricula. Their evaluations also differ from university to university both in content and format. However, finally again they are ranked together, by standardizing the final outcome measure from respective universities, using complex statistical methods. Therefore we believe another way to compare selection 
criteria with outcome measure is by using the common merit order. Because of that we looked at the correlation between final order of merit of medical graduates and GCE A/L attempt and aggregate. GCE A/L mark showed a statistically significant negative correlation to merit position (numerical value). In other words a student who obtained a higher mark at GCE A/L examination also obtained a higher position in merit order (low numerical value). Similarly the attempt of entry showed a positive correlation to the final merit position (numerical value). In other words second or third attempter (at GCE A/L) will get a low position in the order of merit ie. high numerical value. Although the strength was low in both instances, it was statistically significant. The strength could have been low because the final order of merit is not formulated from a common examination as of GCE A/L, but by using assessment schemes adopted by individual medical faculties and statistically collating them.

Based on the experience from the Colombo medical faculty as well as from other medical faculties in the island, we believe that limiting the intake to first and second GCE $\mathrm{A} / \mathrm{L}$ attempt would help to produce a better qualified doctor. Moreover it may be unjust to waste a student's additional year of life to complete a third attempt and if successful for them to waste further time at university by repeating examinations. This may aggravate student frustration and perhaps underutilize a human resource. Some of the third attempters may have sat for the GCE $\mathrm{A} / \mathrm{L}$ examination to satisfy the wishes of parents rather than to fulfill their ambitions, thus unnecessarily exposing them to huge psychological stresses.

We believe that the number of attempts to sit for GCE A/L in order to gain entry to a medical school as well as other degree courses should be confined to two attempts. This will help to conserve many resources as well as guide these youths to more productive fields which would suit them better. Many medical schools around the world use non-cognitive factors such as personality, learning styles, language skills, skills in sports etc in addition to academic ability to select medical undergraduates. However, none have developed a fool proof method to select the best students to study medicine and are under constant criticism. Due to intense competition to enter a medical school, allegations crop up frequently regarding selection criteria especially when more non-cognitive, less objective criteria are used. It is always better to use a combination of factors rather that one or two selection criteria. Until a better method is devised; the ideal would be to use the past cognitive ability combined with the number of attempts and perhaps English language proficiency. Majority of students enter Colombo medical school on merit. Therefore there may be some "selection bias" in the student population and it may be difficult to extrapolate these results to other medical schools of the country. Therefore more wide spread research is needed involving all medical schools in the country, before arriving at a final decision on this nationally important but very sensitive issue of selecting the most suitable to become medical undergraduates. Since GCE A/L 1998 batch, a common multiple choice question paper for each subject at final MBBS examination had been introduced. This is being prepared on a common format by a single group of examiners. Therefore this could be used as an outcome variable and would be possible to compare the performance of medical students between universities. 


\section{References}

1. Ferguson A., James D., Madeley L. Factors associated with success in medical school: review of the literature. British Medical Journal 2002; 324: 952-957.

2. Bandaranayake R.C. Selection of students to medical school. The Ceylon Medical Journal 2005; 50: 41-43.

3. De Silva N.R., Pathmeswaran A., de Silva H.J. Selection of students for admission to a medical school in Sri Lanka. The Ceylon Medical Journal 2004; 49: 81 85.

4. Amerasinghe D.M., Basnayake V. Student performance at the second examination for medical degrees in the Faculty of Medicine at Peradeniya, related to the GCE (A level) selection process. Proceedings of the Kandy Society of Medicine Annual Sessions 1987; 10: 66-68 (abstract).

5. Senanayake N., Weerasinghe V. Does the advanced level aggregate score reflect subsequent performance of a student in the medical faculty? Proceedings of the Kandy Society of Medicine Annual Sessions 1996; 19: 38 (abstract).

6. Wickramasinghe V.P., Kudolugoda Arachchi J., Lamabadusuriya S.P., Kottahachchi D., Ajanthan R. Analysis of the performance of 8 batches of medical students in the Faculty of Medicine, University of Colombo; of 2 different curricula. International Conference on Curriculum Change in Medical Schools. Colombo, Sri Lanka. July 2002; Abstract; FP 17: 26-27.

7. Rajapakse L. Selection of students for admission to a medical school in Sri Lanka. Ceylon Medical Journal 2004; 49: 147.

8. Dawson B., Trapp R.G. Basic and clinical biostatistics. 3rd ed. International edition. Lange Medical Books/McGraw-Hill, 2001. 